\title{
Indicators of Functional Dependency and Institutionalization in the Elderly Population
}

\section{Martinez Suarez PC and Juarez V Ramos}

National Education University, Azogues, Ecuador

*Corresponding author: Dr. Juarez Ramos V, National Education University, Azogues, Ecuador, Tel: 5932 3985000; E-mail: veronica.juarez@unae.edu.ec Rec date: Feb 08, 2016; Acc date: Feb 23, 2016; Pub date: Feb 26, 2016

Copyright: (c) 2016 Suarez PCM, et al. This is an open-access article distributed under the terms of the Creative Commons Attribution License, which permits unrestricted use, distribution, and reproduction in any medium, provided the original author and source are credited.

\section{Introduction}

The main objectives of Gerontology are not only to increase longevity, but it seeks to increase the quality of life [1]. Active aging is the ability of people to adapt to the changes typical of aging in the sense of functionality (can perform daily activities independently) and health promotion. Currently, the capacity of the person, their expectations and their ability to participate in all areas of social life are prolonged much longer than in previous decades. This process is irreversible, universal process, and affects to every individual. In this process a number of physical, psychological and social changes occur, but not at the same time and degree in all people. The inter-individual variability [2] implies that as elderly population tend to be more heterogeneous in the psychological, physiological or social functioning due to biological or biographical factors. Also, we must talk about intra-individual variability which means that if an elder changes in a certain function, behavior, psychological or physiological capacity or ability does not mean that he has to produce changes in other functions. In any case, there are also capabilities that are maintained or may even improve [2]. These changes originate situations of physical and psychological dependence in the elderly.

\section{Fragility}

Fragility in the elderly is "a state that is associated with a biological phenomenon of aging through a loss of functional reserve that causes extreme vulnerability of the organism to stress, being considered as an important predictor of adverse health effects" [3]. Therefore, the identification of risk factors, causes, markers and/or predictors of fragility could be useful in the diagnosis of fragility in the elderly population and as a result, this would improve their quality of care, creating appropriate preventive measures.

\section{Disability}

There are millions of people with a specific disability that makes it difficult to fulfill the functions of the community. The most common are sensory (vision and hearing), following them in importance affecting the osteoarticular system, degenerative processes and mental disorders. Moreover, the care provided to these people is still being supplied by their families. The studies should be directed to the optimization of resources for elder with disabilities in order to the care management would be more effective and less economic dependence.

\section{Dependence}

Aging has several consequences such as increasing dependence and burden of care. Elder population loses contact and social fabric. Social withdrawal, although in principle can be initiated from the elderly, is often increased by the indifference of the environment, leading to the emergence of dependency of them. The limitations of this area include the recognition of the official diagnosis of codependency in Informal caregivers which would allow of an improvement in the quality of care.

\section{Depression}

Studies show that the prevalence of depressive symptoms in institutionalized elderly is high [4] and being depressed is an important predictor of poor quality of life. Studies on coping [5] indicate that in the elderly the main source of support is the family. The social dislocation is a common geriatric syndrome that causes disability and increased mortality in this population. This early diagnosis is critical for the implementation of an adequate and proper treatment.

The limitations of these studies are the construct itself by its multiplicity of pathological manifestations in comorbidity with other disorders.

\section{Dementia and Mild-Cognitive Damage}

These indicators has become the most important [6]. In recent years the use of Mini Mental Test and Hughes functional scale has increased, so this establish a criteria court. Some limitations of these studies are problems in the criteria validity. However, the reliability is guaranteed by universal scales which are easy to implement and have a proper construction. They are designed tests to be administrated in repeated measurements.

Some authors consider malnutrition as an idicator of dependency too. The prevalence of malnutrition was $9.4 \%$ while $55.1 \%$ were at risk of malnutrition [7]. Risk factors for malnutrition was an overnight fast $>11$ hours, $<4$ eating episodes a day, and not cooking independently.

The need of studies about Indicators dependence on elder population is global becuase the phenomenon has an international presence [8].

\section{References}

1. http://www.mapfre.com/salud/es/cinformativo/salud-mayores.shtml.

2. Garcia M, Marquez B, Parra C (2009) Cuidados de enfermeria para satisfacer las necesidades fisiologicas de los ancianos alojados en la Unidad Geriatrica Dr. Carlos Fragachan de Ciudad Bolivar, Estado Bolivar 13-35.

3. Ugartemendia Yerobi M (2011) Estudio de indicadores de fragilidad en ancianos institucionalizados. Master de Investigación en Ciencias de la Salud, Universidad de Navarra 1-55.

4. Carrasco Muniz S (2011) Depresion en el anciano. Hygia revista de enfermeria en internet 78: 62-66.

5. Garrido-Abejar M, Serrano-Parra MD, Bartolome-Gutierrez R, MartinezVizcaino V (2012) Factores asociados con calidad de vida relacionada con 
Citation: Suarez M, Ramos JV (2016) Indicators of Functional Dependency and Institutionalization in the Elderly Population. J Gerontol Geriatr Res 5: 280. doi:10.4172/2167-7182.1000280

Page 2 of 2

la salud en mayores institucionalizados: diferencias entre hombres y mujeres. Enferm Cli 22: 27-34

6. Alcalde J (1998) Entrevista a Ramon Cacabelos. Es mas importante estudiar el Alzheimer que el SIDA. Muy interesante 204.

7. Soderstrom L (2016) Nutritional Screening of Older Adults: Risk Factors for and Consequences of Malnutrition.
8. Harwood RH, Sayer AA, Hirschfeld M (2004) Current and future worldwide prevalence of dependency, its relationship to total population, and dependency ratios. Bull World Health Organ 82: 251-258. 